\title{
Acupuncture as adjuvant general anesthesia on cesarean section
}

\author{
Arief Kurniawan ${ }^{1 *}$, Vita Murniati Tarawan ${ }^{2}$, Tono Djuantono ${ }^{3}$ and Tatang Bisri ${ }^{4}$
}

*Correspondence: fathchair@yahoo.com

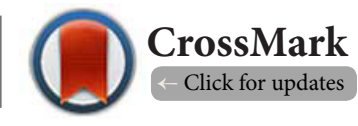

\begin{abstract}
'Department Anesthesia and Intensive Care Dustira Army Hospital Cimahi, Indonesia.
${ }^{2}$ Department Physiology Faculty of Medicine Universitas Padjadjaran Bandung, Indonesia.

${ }^{3}$ Department Obstetry and Gynecology Faculty of Medicine Universitas Padjadjaran/Dr. Hasan Sadikin General Hospital Bandung, Indonesia.

${ }^{4}$ Department Anesthesia and Intensive Care Faculty of Medicine Universitas Padjadjaran/Dr. Hasan Sadikin General Hospital Bandung, Indonesia.
\end{abstract}

\begin{abstract}
Acupuncture has been widely used to induce analgesia. Acupuncture can be used as pain therapy, allergy, inflammation, metabolic disorder, poststroke and adjuvant anesthesia. This case report aims to describe the benefits of acupuncture as an adjuvant of general anesthesia in cesarean section. A 20 years woman G1P0Ao parturien aterm with fetal breech position presented to undergo cesarean section in general anesthesia with an adjuvant acupuncture at Dr. Dustira Hospital Cimahi Indonesia in June 20th, 2017. Patient was treated electroacupuncture by inserting needles at the points of incision, Hegu (LI-4), Neikuan (P-6), Sanyinjiao (SP-6) and Zusanli (S-36) bilaterally $10 \mathrm{~mA}$ at a frequency of $40 \mathrm{~Hz}$ began 30 minutes before induction of anesthesia until surgery was completed. Induction of anesthesia was initiated by injection of fentanyl $50 \mu \mathrm{g}$ and propofol $50 \mathrm{mg}$ until negative eyelids reflex followed by ventilation support with isofluran, $\mathrm{N} 2 \mathrm{O}: \mathrm{O} 2$, atracurium $25 \mathrm{mg}$ and then performed intubation. Maintenance of anesthesia used isofluran to achieve adequate anesthesia level with BIS monitor on 40-60 scale, $\mathrm{N} 2 \mathrm{O}: \mathrm{O} 2=2 \mathrm{~L} / \mathrm{min}: 2 \mathrm{~L} / \mathrm{min}$. During operation the hemodynamic condition was stable with an average of end tidal isofluran $0.5 \mathrm{vol} \%$. The baby was born with APGAR score of 5-8-10. After surgery the acupuncture needle at the left Hegu point is maintained for 24 hours. Patient was not given either analgesic or antiemetic postoperatively. The patient was admitted to the recovery room for 30 minutes without any complaint of bleeding, pain, nausea or vomiting, then moved to the nursing ward. In this case, acupuncture as adjuvant general anesthesia decreased the dose of anesthetic drugs and did not interfere with the fetus. Acupuncture was also useful to prevent postoperative pain and nausea vomiting.
\end{abstract}

Keywords: Acupuncture, adjuvant anesthesia, caesarean section, electroacupuncture

\section{Introduction}

Acupuncture can be used as therapy of pain, allergy, inflammation, metabolic disorder, poststroke and adjuvant anesthesia. Acupuncture has been widely used to induce analgesia. There are two techniques in acupuncture therapy, namely manual acupuncture and electroacupuncture. Electroacupuncture is a modified form of traditional manual acupuncture. The advantage of electroacupuncture is to have the combined therapeutic effect of transcutaneous electrical nerve stimulation (TENS) and manual acupuncture. Most studies use electroacupture because the frequency, voltage, shape and wave length can be standardized $[1,2]$.

Understanding of acupuncture is very important for anesthesiologists since acupuncture can be used as an adjuvant of general anesthesia to decrease the dosage of anesthetic drugs and also to increase postoperative outcomes [3].

This case report aims to describe the benefits of acupuncture as an adjuvant of general anesthesia in patient undergoing 
cesarean section.

\section{Case presentation}

\section{Anamnesis}

A 20 years old woman, G1P0A0 parturien aterm with fetal breech position presented to undergo elective cesarean section in general anesthesia with adjuvant acupuncture on June 20th, 2017 at Dr. Dustira Hospital Cimahi Indonesia. She had never had surgery before. Her complaint of disease was denied before and during pregnancy.

\section{Physical examination}

The patient showed composmentis consciousness, weight $72 \mathrm{~kg}$, height $163 \mathrm{~cm}$, blood pressure $123 / 71 \mathrm{mmHg}$, pulse rate $86 \mathrm{x} /$ minute, respiration rate $22 \mathrm{x} /$ minute, temperature $36,5^{\circ} \mathrm{C}$. The results of airway, heart and lung examination were in the normal limit. Auscultation of the fetus was obtained FHR $120 \mathrm{x} /$ minute.

\section{Laboratory test}

From laboratory examination obtained $\mathrm{Hb} 12 \mathrm{gr} \%$, Leucocyte 10.500 /mcL, Erythrocyte 4.2 millions / mcL, Platelet: 350.000 $/ \mathrm{mm} 3$, Cholesterol: $215 \mathrm{mg} / \mathrm{dl}$, Ureum $13.5 \mathrm{mg} / \mathrm{dl}$, Creatinine $0.8 \mathrm{mg} / \mathrm{dl}$, SGPT $56 \mathrm{U} / \mathrm{L}$, SGOT $27 \mathrm{U} / \mathrm{L}$, Glucose $110 \mathrm{mg} / \mathrm{dl}$.

\section{Anesthetic management}

Patient was treated electroacupuncture by inserting needles at the points of incision, Hegu (LI-4), Neikuan (P-6), Sanyinjiao (SP-6) and Zusanli (S-36) bilaterally (Figures 1 and 2), powered $10 \mathrm{~mA}$ at a frequency of $40 \mathrm{~Hz}$ that began 30 minutes before induction of anesthesia until surgery was completed. Induc-

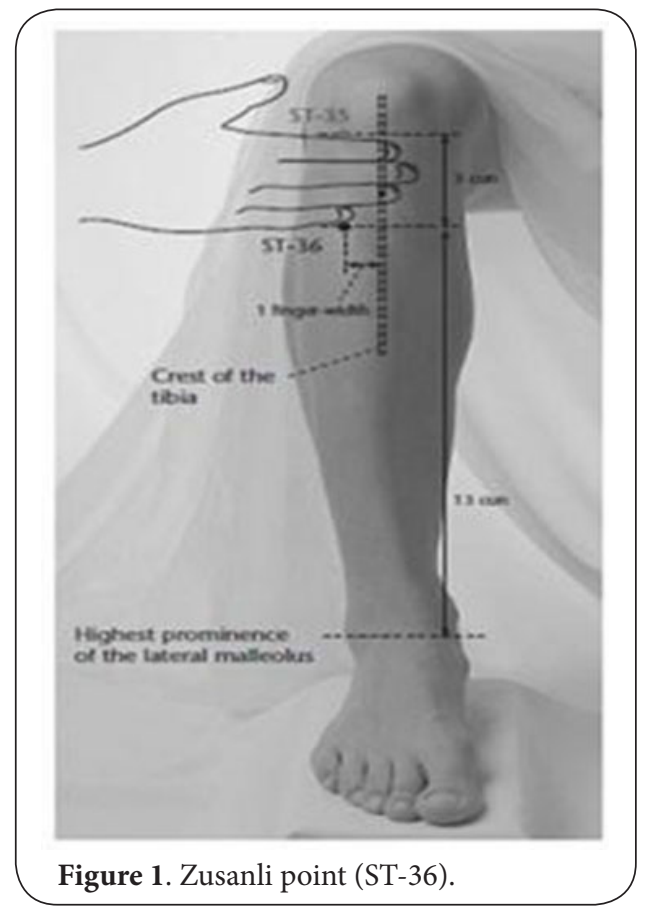

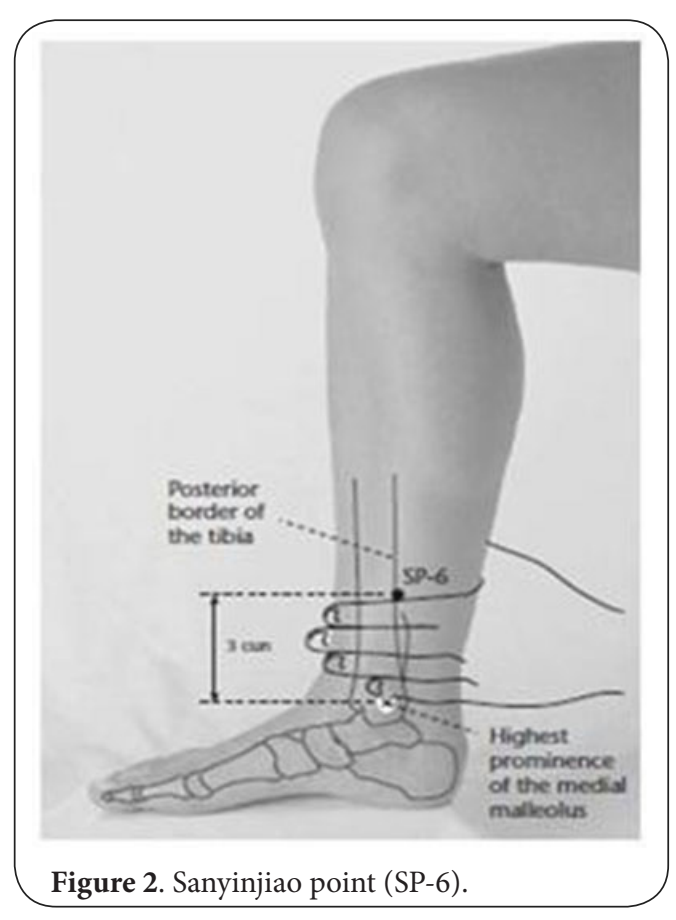

tion of anesthesia began with fentanyl $50 \mu \mathrm{g}$ and propofol $50 \mathrm{mg}$ injection until negative eyelids reflex followed by ventilation support with isoflurane, N2O: O2, atracurium 25 $\mathrm{mg}$ then intubation. Maintenance of anesthesia used isoflurane to achieve adequate anesthesia level with BIS monitor at scale 40-60, N2O: O2=2:2 L/minute. The average of end tidal isofluran was 0.5 vol\%. Conditions of preoperative, intraoperative, postoperative blood pressure, pulse rate and peripheral oxygen saturation were stable (Figure 3 ). The baby was born with score APGAR of 5-8-10.

\section{Postanesthesia care}

After surgery the acupuncture needle at the left Hegu point was maintained for 24 hours. Patient was not given either

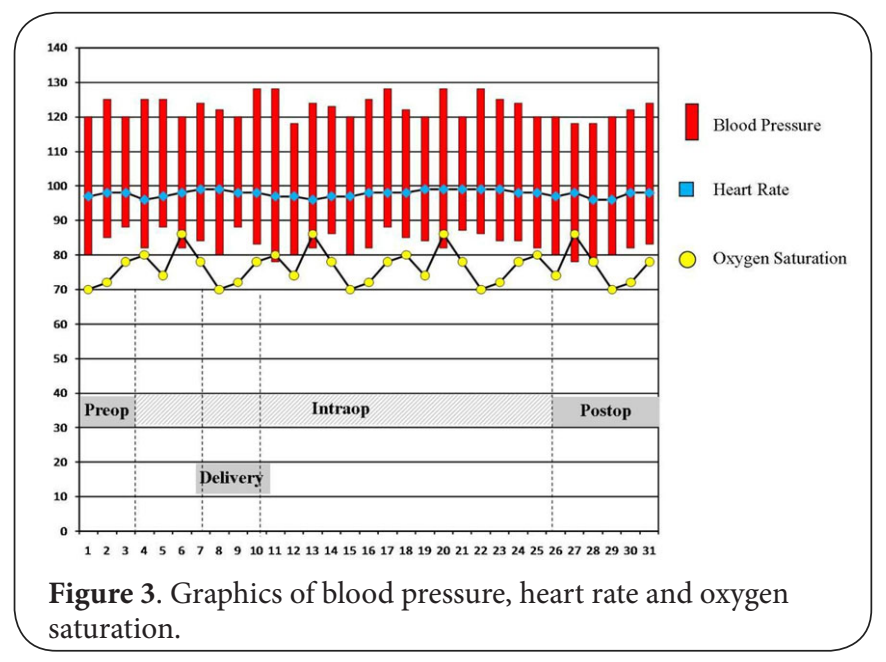


postoperative analgesic or antiemetic. The patient was admitted to the recovery room for 30 minutes without any complain of bleeding, pain, nausea or vomiting, and then moved to the ward.

\section{Discussion}

Based on this case, the patient underwent cesarean section for indication of breech position. Patient preferred general anesthesia during surgery after obtaining explanation of anesthesia techniques and agreed to receive adjuvant acupuncture. There are various indications in cesarean section. The most common indications are previous cesarean section, breech position, dystocia, and fetal distress [4]. The incidence of breech presentation in the fetus is 3-4\%. In the breech presentation, an external version can be performed to alter the presentation of the fetus. If an external version does not work, then elective cesarean delivery may be performed [5]. Complications can occur in cesarean section such as infection (surgical wound, uterus, puerperium), wound hematoma or disruption, laceration of urinary vesica, ureteral trauma, extension of hospitalization, anesthesia complication, hysterectomy, hypovolemic shock, heart failure, venous thromboembolism and death [6]. The risk of death from a cesarean section is 2.2 per 100,000 deliveries of 1.5 million pregnancies, in which emergency cesarean section has a 9-fold greater risk while elective cesarean section has a 3-fold risk for maternal death [7].

The choice of anesthesia technique used in cesarean section is a regional or general anesthesia that has both advantages and disadvantages. The choice of anesthesia depends on indication of surgery, degree of urgency, state of the mother, and patient's desire [8].

General anesthesia is often associated with the occurrence of neonatal depression that often requires resuscitation. The advantage of general anesthesia is the procedure works more quickly so that it is often done in cases of the time speed being the main factor, decreasing the incidence of hypotension as well as cardiovascular instability, airway and ventilation are controlled. Regional anesthesia provides several advantages including the mother will remain awake, to reduce the possibility of aspiration and avoid neonatal depression. The side effects of hypotension and bradycardia are the most frequent process of physiological changes due to spinal anesthesia. Spinal anesthesia can result in a sharp decline of maternal blood pressure that affects mother and baby $[9,10]$.

Acupuncture as anesthetic adjuvant may be useful for preoperative sedation, reduced use of intraoperative opiates, postoperative management of pain and nausea vomiting. Acupuncture can stabilize heart function and attenuate the adverse effects of anesthesia and surgery. The purpose of acupuncture treatment is to optimize the patient's physiological and psychological conditions, reduce preoperative anxiety, and trigger the release of endogenous opiates such as $\beta$-endorphins. Acupuncture triggers the release of opiates that have analgesic and sedative effects may be used to decrease the dose of inhaled anesthetic [11,12].

Acupuncture works by affecting the innervation of the inner lining tissue, muscle, connective tissue and pain fibers. Acupuncture points are located in tight neural areas, especially pain nerve fibers. Electroacupuncture stimulates $A \beta$ fibers and modulates Nucleus Rafe Magnus (NRM) to produce analgesia. Acupuncture exerts an effect through central and peripheral mechanisms evidenced by both experimental of human and animal studies and also involves various bioactive chemicals or mediators as shown in Figure $4[13,14]$.

Low frequency acupuncture $(2-15 \mathrm{~Hz})$ may release enkephalin, $\beta$-endorphin and endomorphin acting on $\mu$ and $\kappa$ receptors. High frequency acupuncture $(100 \mathrm{~Hz})$ causes the release of dinorphine for $\mathrm{k}$ receptors on the spinal nerve. Acupuncture involves opiates, cholecystokinin octapeptide (CCK-8), 5-hydroxytryptamine (5-HT), N-methyl D-aspartateAcid (NMDA) and other antiinflammatory and analgesic mediators (angiotensin, somatostatin, vasopressin, arginine and neurotensin) $[15,16]$.

In this case, the general anesthetic use of propofol, fentanyl and isoflurane are lower due to the effect of adjuvant acupuncture which has analgesic and sedative effects. Acupuncture plays a role in reducing pain in surgery by increasing plasma $\beta$-endorphin levels. In addition to analgesic effect, acupuncture also has a sedative effect due to opiate stimulation $[17,18]$. Acupuncture can reduce the need of volatile anesthetic. Electroacupuncture study resulted in a slight reduction the need of halothane in anesthezied animals but statistically was significant. The advantage of acupuncture during general anesthesia is to allow full blind study without sham treatment [19].

APGAR scores are normal and not affected by acupuncture. Previous research has shown that acupuncture is safe and combined with conventional anesthesia techniques capable of reducing the opiate dose and providing more convenient postoperative conditions than pure anesthesia [20-22].

Patient was not given postoperative analgesic and antiemetic medication but had no pain or nausea vomiting. The acupuncture needle at the left Hegu (LI-4) point maintained until the postoperative period provided analgesic and antiemetic effects.

Acupuncture as adjuvant controls pain and eliminates opiate side effects in the postoperative period. An acupuncture study designed with noninserted placebo treatment was administered twice that is immediately after the surgical procedure and after the patient reported moderate pain.

The result showed that postoperative pain was significantly longer in placebo group than acupuncture group. The average consumption of analgesics was significantly reduced in the acupuncture group [23]. Electroacupuncture stimulation on anesthesized patients with respiratory control were performed in 12 patients, of which 10 patients underwent brain surgery and 2 patients underwent HNP surgery. The results showed a better effect on this treatment than with classical anesthesia. 


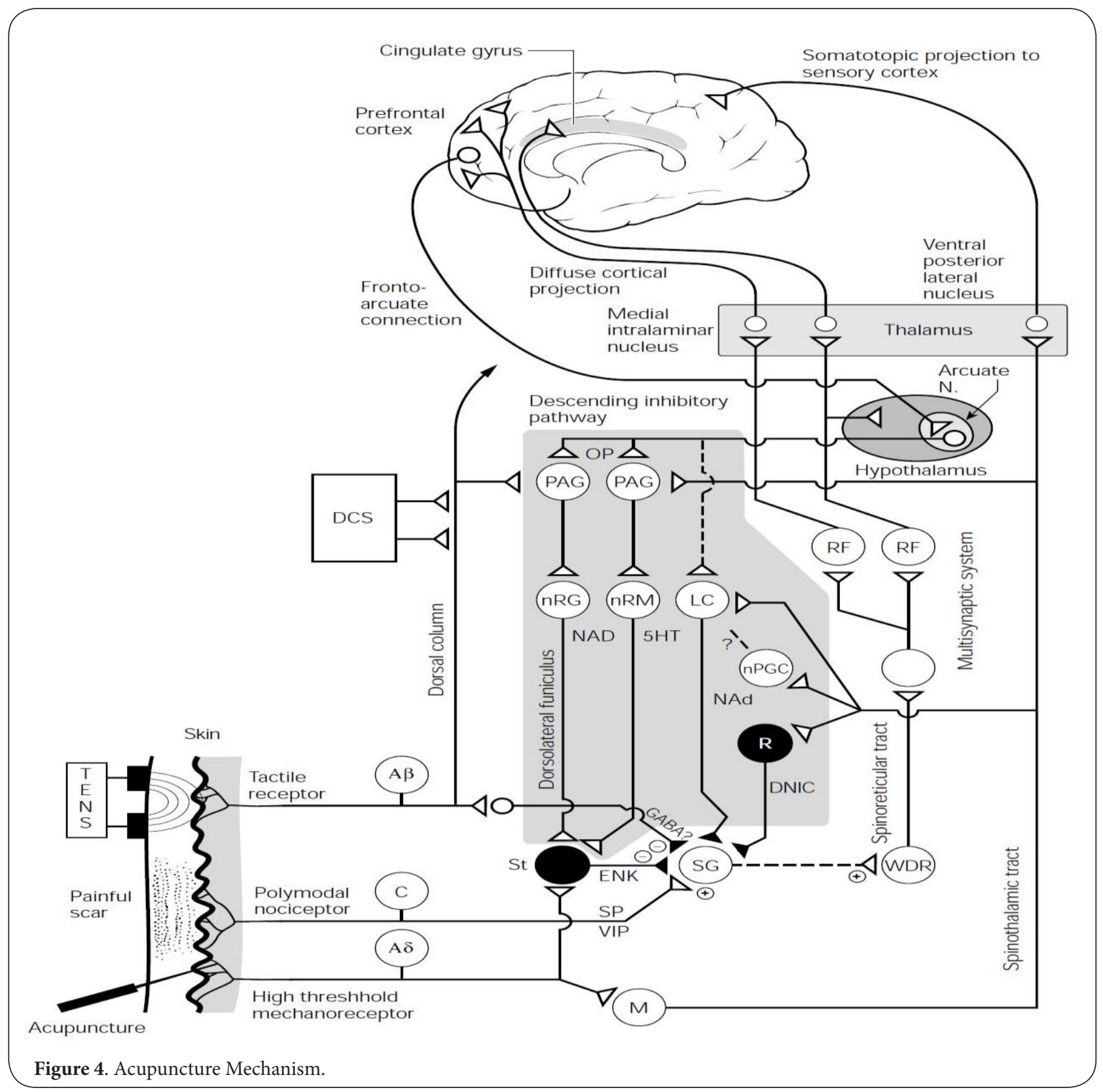

Patients had stable intraoperative haemodynamic, relaxed brain, waking up and better postoperative analgesia [16].

Previous studies that examined the effects of acupuncture on postoperative nausea vomiting showed that acupuncture reduced the incidence of nausea of vomiting in surgical ton-

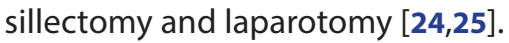

\section{Conclusions}

Acupuncture as adjuvant general anesthesia in cesarean section lowers the dose of anesthetic drugs and does not interfere with the fetus. Acupuncture is also useful to prevent postoperative pain and nausea vomiting.

\section{Competing interests}

The authors declare that they have no competing interests.

Authors' contributions

\begin{tabular}{|l|c|c|c|c|}
\hline Authors' contributions & AK & VMT & TD & TB \\
\hline Research concept and design & -- & -- & -- & $\checkmark$ \\
\hline Collection and/or assembly of data & $\checkmark$ & -- & -- & -- \\
\hline Data analysis and interpretation & $\checkmark$ & -- & -- & $\checkmark$ \\
\hline Writing the article & $\checkmark$ & -- & -- & -- \\
\hline Critical revision of the article & -- & $\checkmark$ & $\checkmark$ & $\checkmark$ \\
\hline Final approval of article & $\checkmark$ & $\checkmark$ & $\checkmark$ & $\checkmark$ \\
\hline Statistical analysis & -- & -- & -- & -- \\
\hline
\end{tabular}


Kurniawan et al. Journal of Anesthesiology \& Clinical Science 2018, http://www.hoajonline.com/journals/pdf/2049-9752-7-3.pdf

\section{Publication history}

EIC: D. John Doyle, Case Western Reserve University, USA

Received: 09-May-2018 Final Revised: 01-Jun-2018

Accepted: 06-Jun-2018 Published: 18-Jun-2018

\section{References}

1. Ning $Z$ and Lao L. Acupuncture for Pain Management in Evidence-based Medicine. J Acupunct Meridian Stud. 2015; 8:270-3. | Article | PubMed

2. Focks C. Acupuncture points. In: Focks, ed. Atlas of Acupuncture. 7th ed. London: Churchill Livingstone; 2008; 104-380.

3. Madsen MV, Gotzsche PC and Hrobjartsson A. Acupuncture treatment for pain: systematic review of randomised clinical trials with acupuncture, placebo acupuncture, and no acupuncture groups. BMJ. 2009; 338:a3115. | Article | PubMed Abstract | PubMed FullText

4. Chesnut DH, Polley LS, Tsen LC and Wong CA. Obstetric anesthesia, principles and practice. 4th ed. Philadelphia: Mosby Elseiver; 2009; 153-66.

5. Birnbach DJ, Browne IM. Anesthesia for obstetrics. In: Miller RD, ed. Anesthesia. 6th ed. New York: Churchill Livingstone Inc; 2005; 2307-26.

6. Gori F, Pasqualucci A, Corradetti F, Milli M and Peduto VA. Maternal and neonatal outcome after cesarean section: the impact of anesthesia. J Matern Fetal Neonatal Med. 2007; 20:53-7. I Article I PubMed

7. Casey BM, Mclntire DD and Leveno KJ. The continuing value of the Apgar score for the assessment of newborn infants. N Engl J Med. 2001; 344:467-71. | Article | PubMed

8. Afolabi BB, Lesi FE and Merah NA. Regional versus general anaesthesia for caesarean section. Cochrane Database Syst Rev. 2006; CD004350. I Article | PubMed

9. Algert CS, Bowen JR, Giles WB, Knoblanche GE, Lain SJ and Roberts CL. Regional block versus general anaesthesia for caesarean section and neonatal outcomes: a population-based study. BMC Med. 2009; 7:20. | Article | PubMed Abstract | PubMed FullText

10. Birnbach DJ. General anesthesia for cesarean section-who needs it? European Society of Anaesthesiologists, Refresher Course. 2003; 165-7.

11. Chernyak GV and Sessler DI. Perioperative acupuncture and related techniques. Anesthesiology. 2005; 102:1031-49. | Article I PubMed Abstract | PubMed FullText

12. Zhou F, Huang D and Xia Y. Acupuncture mechanism. In: Zhou, ed. Neuroanatomical Basis of Acupuncture Points. 2nd ed. Beijing: Tsinghua University Press. 2010; 32-80.

13. Leung L. Neurophysiological basis of acupuncture-induced analgesia-an updated review. J Acu Meridian Studies. 2012; 5:261-70.

14. Zhang R, Lao L, Ren K and Berman BM. Mechanisms of acupunctureelectroacupuncture on persistent pain. Anesthesiology. 2014; 120:482503. | Article | PubMed Abstract | PubMed FullText

15. Gim GT, Lee JH, Park E, Sung YH, Kim CJ, Hwang WW, Chu JP and Min BI. Electroacupuncture attenuates mechanical and warm allodynia through suppression of spinal glial activation in a rat model of neuropathic pain. Brain Res Bull. 2011; 86:403-11. | Article | PubMed

16. Gheorghita E, Litarczek G, Trifu M, Rata O, Ciurea J and Gorgan RM. Anesthesia by electroacupuncture in neurosurgery. Romanian Neurosurgery. 2010; 3:348-53.

17. Hargreaves KM. Plasma beta-endorphin levels in oral surgery patients following diazepam, fentanyl or placebo. Anesth Prog. 1984; 31:124-9. | PubMed Abstract | PubMed FullText

18. Xiang XC and Zhang P. How acupuncture works? Neuroscientific basis underlying acupuncture analgesia. Chinese Acupuncture Association. 2012. I Website

19. Tseng CK, Tay AA, Pace NL, Westenskow DR and Wong KC. Electroacupuncture modification of halothane anaesthesia in the dog. Can
Anaesth Soc J. 1981; 28:125-8. I PubMed

20. Kotani N, Hashimoto H, Sato Y, Sessler DI, Yoshioka H, Kitayama M, Yasuda T and Matsuki A. Preoperative intradermal acupuncture reduces postoperative pain, nausea and vomiting, analgesic requirement, and sympathoadrenal responses. Anesthesiology. 2001; 95:349-56. | Article I PubMed

21. Kho HG, van Egmond J, Zhuang CF, Lin GF and Zhang GL. Acupuncture anaesthesia. Observations on its use for removal of thyroid adenomata and influence on recovery and morbidity in a Chinese hospital. Anaesthesia. 1990; 45:480-5. | Article | PubMed

22. Cheng TO. Stamps in cardiology. Acupuncture anaesthesia for open heart surgery. Heart. 2000; 83:256. | Article | PubMed Abstract | PubMed FullText

23. Lao L, Bergman S, Hamilton GR, Langenberg P and Berman B. Evaluation of acupuncture for pain control after oral surgery: a placebo-controlled trial. Arch Otolaryngol Head Neck Surg. 1999; 125:567-72. | Article | PubMed

24. Dundee JW, Chestnutt WN, Ghaly RG and Lynas AG. Traditional Chinese acupuncture: a potentially useful antiemetic? Br Med J (Clin Res Ed). 1986; 293:583-4. | PubMed Abstract | PubMed FullText

25. Al-Sadi M, Newman B and Julious SA. Acupuncture in the prevention of postoperative nausea and vomiting. Anaesthesia. 1997; 52:658-61. | Article | PubMed

\section{Citation:}

Kurniawan A, Tarawan VM, Djuantono T and Bisri $\mathrm{T}$. Acupuncture as adjuvant general anesthesia on cesarean section. J Anesthesiol Clin Sci. 2018; 7:3. http://dx.doi.org/10.7243/2049-9752-7-3 